\title{
Disseminated Intravascular Coagulation at Diagnosis in Acute Myeloblastic Leukaemia
}

\author{
Masba Uddin Chowdhury ${ }^{*}$, Masuda Begum², Md. Rafiquzzaman Khan², Amin Lutful Kabir ${ }^{2}$, \\ Shafiqul Islam², Khushbun Nahar Layla ${ }^{3}$, Fahmida Ahamed ${ }^{4}$, Jamal Uddin Tanin ${ }^{5}$
}

\author{
${ }^{1}$ Department of Haematology \& HSCT, Evercare Hospital, Dhaka, Bangladesh \\ ${ }^{2}$ Department of Haematology, Bangabandhu Sheikh Mujib Medical University, Dhaka, Bangladesh \\ ${ }^{3}$ Department of Physiology, Ibrahim Medical College \& Hospital, Dhaka, Bangladesh \\ ${ }^{4}$ Department of Haematology, Imperial Hospital Limited, Chittagong, Bangladesh \\ ${ }^{5}$ Parkview Hospital, Chittagong, Bangladesh \\ Email: *cmasba@gmail.com, masudabegumk34@gmail.com, drkhan64@gmail.com, aminlutful@gmail.com, \\ shafiqhematology@gmail.com, laylaluna7671@gmail.com,drfahmidaahamed@gmail.com,drtanincmc@gmail.com
}

How to cite this paper: Chowdhury, M.U., Begum, M., Khan, Md.R., Kabir, A.L., Islam, S., Layla, K.N., Ahamed, F. and Tanin, J.U. (2021) Disseminated Intravascular Coagulation at Diagnosis in Acute Myeloblastic Leukaemia. Journal of Biosciences and Medicines, 9, 124-134.

https://doi.org/10.4236/jbm.2021.910011

Received: September 15, 2021

Accepted: October 19, 2021

Published: October 22, 2021

Copyright $\odot 2021$ by author(s) and Scientific Research Publishing Inc. This work is licensed under the Creative Commons Attribution International License (CC BY 4.0).

http://creativecommons.org/licenses/by/4.0/

\begin{abstract}
Background: Disseminated Intravascular Coagulation (DIC) is a life threatening complication frequently observed in acute leukemia. Among the morphological varieties of Acute Myeloid Leukaemia (AML), Acute Promyelocytic Leukaemia (APL) is well established to cause DIC. But there have been reports noted that abnormal DIC parameters also commonly observed in the patients with non-APL AML. This study evaluated the DIC parameters \& DIC score according to International Society of Thrombosis and Haemostasis (ISTH) in newly diagnosed non-APL AML patients. Materials and Methods: This cross-sectional observational study was conducted in the Department of Haematology, BSMMU, Dhaka, Bangladesh. 48 newly diagnosed non-APL AML patients were enrolled. Platelets count was measured by auto analyzer (Sysmax XT 2000i/Pentra ABX-120DX) as well as checked manually. Prothrombin time, fibrinogen, D-Dimer were measured using STAGO Coagulation analyzer. The ISTH-DIC scoring system was used to calculate DIC score. The statistical analysis was carried out using the Statistical Package for Social Sciences version 24.0 for Windows. Chi-Square test \& Fisher exact test was used for categorical variables. Unpaired t-test was used to compare mean between groups. For all statistical tests, $p$-value less than 0.05 was considered as statistically significant. Results: By analyzing 48 newly diagnosed patients with non-APL AML, found that DIC developed in $14.6 \%$ patients at presentation. Among the DIC parameters, PT and D-dimer were significantly higher in patients presented with DIC. Patients with DIC exhibit lower expression of CD117, CD34, HLA-DR and statistically significant association with negative expression of HLA-DR ( $p$-value 0.034 ). No significant association was found
\end{abstract}


between presence of DIC and age, gender, bleeding at presentation, morphological type, WBC count or peripheral blast percentage. Conclusion: Abnormalities of DIC parameters in common in patients with AML. A significant portion of patients with DIC have no apparent symptom or bleeding. So, routine screening of DIC parameter at presentation is recommended for early diagnosis \& effective management of DIC.

\section{Keywords}

Acute Myeloblastic Leukaemia, Disseminated Intravascular Coagulation, ISTH-DIC Scoring System

\section{Introduction}

Acute myeloid leukaemia (AML) is a heterogeneous disorder characterized by clonal expansion of myeloid progenitors (blasts) in the bone marrow and peripheral blood [1]. Disseminated intravascular coagulation (DIC) is a syndrome characterized by the systemic activation of blood coagulation, which generates intravascular thrombin and fibrin, resulting in the thrombosis of small to medium-sized vessels and ultimately organ dysfunction and severe bleeding [2] [3]. Thrombohemorrhagic complications are common in patients suffering from malignancy [4]. Clinical manifestations vary from localized deep venous thrombosis which frequently observed in solid tumors, to life-threatening bleeding due to DIC with consumption of platelets \& clotting factors, which is generally associated with haematological malignancy [5]. Patients with leukaemia commonly present with abnormal coagulation parameters, even without features of thromboembolism or haemorrhage. These findings demonstrate different degrees of blood clotting activation and characterize the hypercoagulable state in these patients [6] [7]. Though DIC is frequently a presenting feature of acute promyelocytic leukaemia, data regarding other forms of acute leukaemia is variable.

Disseminated intravascular coagulation has been reported in $10 \%$ to $40 \%$ of patients at presentation in various series of patients with acute leukaemia [8]. The ISTH (International Society of Thrombosis and Haemostasis) overt DIC score has been shown to be sensitive to DIC of infective and non-infective etiologies [9] [10]. The sensitivity of the ISTH overt DIC score is $91 \%$ with a specificity of $97 \%$ [11]. A strong correlation between an increasing DIC score and mortality has been demonstrated by various series of study. Several studies have confirmed that the presence of overt DIC by the ISTH algorithm is independently predictive of mortality [9] [12] [13]. Libourel et al., (2016) reported the incidence and risk factors for thrombosis in newly diagnosed adults with acute myeloid leukaemia (AML) [14]. Their data suggested a thrombosis prevalence of $8.7 \%$ in younger and $10.4 \%$ in older adults with AML, patients at greater risk exhibit disseminated intravascular coagulation (DIC) at diagnosis and high D-dimer levels in particular. They establish that disseminated intravascular coagulation at 
diagnosis is a strong predictor for thrombosis in acute myeloid leukaemia. The risk of thrombosis in those with overt DIC is over $20 \%$ in younger patients with AML and up to $40 \%$ in older patients [14].

So, screening and evaluation of DIC parameter in newly diagnosed AML patients will be helpful to find out the pattern of DIC parameters abnormality in AML patients, to identify patients with overt DIC early \& to start treatment accordingly. This study will also be helpful to identify factors associated with the development of DIC and to identify patients are at increased risk of developing thrombosis.

\section{Materials and Methods}

This cross-sectional observational study was conducted in the Department of Haematology, BSMMU, Dhaka, Bangladesh from September 2016 to February 2018. 48 newly diagnosed AML patients were enrolled. Patients with APL confirmed by morphology \& molecular study were excluded from the study. Ethical issues were addressed to every patient. Ethical clearance was obtained from institutional review board (IRB) of BSMMU. Informed written consent was taken from the study population. For PT, D-dimer \& fibrinogen assay $2.7 \mathrm{ml}$ blood was collected in tri-sodium citrate (3.8\%) containing tube. After rotating the tube at $2000 \mathrm{rpm}$ for $20 \mathrm{~min}$ sample was put in auto analyzer STAGO Coagulation analyzer (Diagnostica Stago, Asnières, France). The STA-Liatest D-Di kit (Diagnostica Stago) was used for quantitative determination of D-dimer in plasma by immune-turbidimetric method. The STA-fibrinogen kit (Diagnostica Stago) was used with STA-R analyzers for the quantitative determination of Fibrinogen levels in plasma using the clotting method of Clauss. The STA-néoplastine $\mathrm{Cl}$ Plus was used with STA-R analyzers for the determination of PT. To measure platelets count $3 \mathrm{ml}$ blood was collected in EDTA containing tube, then was put into the auto analyzer (Sysmax XT 2000i/Pentra ABX-120DX). Platelets count was checked manually, any discrepancy of results were retested. The ISTH-DIC scoring system was used to calculate DIC score and a cut of value of $\geq 5$ is used for overt DIC (Table 1) [15]. The statistical analysis was carried out using the Statistical Package for Social Sciences version 24.0 for Windows (SPSS Inc., Chicago, Illinois, USA). Qualitative variables (e.g. sex, morphological varieties of AML) of this study were expressed as percentage. Quantitative variable (e.g. age, platelet count) were expressed as mean \pm standard deviation. Chi-Square test \& Fisher exact-test were used for categorical variables. Unpaired t-test was used to compare mean of two groups. For all statistical tests, $p$-value less than 0.05 was considered as statistically significant.

\section{Results and Discussions}

Disseminated intravascular coagulation is responsible for most cases of clinically significant bleeding or thrombosis in acute leukaemia [16]. Although more commonly recognized in association with acute promyelocytic leukaemia, all 
Table 1. Scoring system for overt disseminated intravascular coagulation (DIC) according to ISTH-DIC scoring system [15].

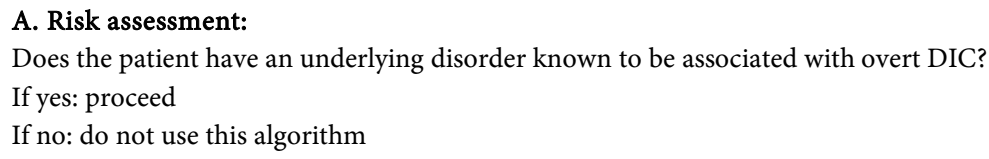

B. Order global coagulation tests:

PT, platelet count, fibrinogen, fibrin related marker

\section{Score the test results}

1) Platelet count $\left(\geq 100 \times 10^{9} / 1=0,<100 \times 10^{9} / 1=1,<50 \times 10^{9} / 1=2\right)$

2) Elevated fibrin marker (e.g. D-dimer, fibrin degradation products) (no increase $=0$, moderate increase $=2$, strong increase $=3$ )

3) Prolonged PT ( $<3 \mathrm{~s}=0,>3$ but $<6 \mathrm{~s}=1,>6 \mathrm{~s}=2)$

4) Fibrinogen level $(>1 \mathrm{~g} / \mathrm{l}=0,<1 \mathrm{~g} / \mathrm{l}=1)$

D. Calculate score:

$\geq 5$ : compatible with overt DIC, repeat score daily

$<5$ : suggestive for non-overt DIC, repeat next $1-2 \mathrm{~d}$

types of acute myeloid leukaemias can trigger DIC. The mechanism by which the malignant cells play a role in the pathogenesis of coagulopathy has not been completely clarified, although 2 hypotheses have been proposed. The first theory suggests that the granules of the malignant cells contain enzymes that can nonspecifically degrade proteins, including plasma coagulation factors. The second theory focuses on the presence of tissue factor-like material in the granules of leukaemic cells that lead to activation of the coagulation cascade when they are released. Secretion of inflammatory cytokines by leukaemic cells, the introduction of cytotoxic chemotherapy, and concomitant infections can all produce DIC [17]. The present study was undertaken to find out the frequency of overt DIC at presentation and to identify clinical parameters associated with DIC.

In this study, the median age was 40 years (range, 16 - 70 years), 25 patients (52.1\%) were males and 23 (47.9\%) were females (Table 2). Morphologically the distribution was AML M0: 2 (4.8\%), AML M1: 7 (16.7\%), AML M2: 20 (47.6\%), AML M4: 10 (23.8\%), AML M5: 2 (4.8\%), and AML M6: 1 (2.4\%). Patients with acute promyelocytic leukaemia (AML M3) were excluded from the study.

ISTH (International Society of Thrombosis and Haemostasis) DIC criteria was used, because it is more specific to diagnose overt DIC than other proposed criteria and using cut off 5 in ISTH score has a sensitivity of $91 \%$ and specificity of 97\% for DIC [11]. Although these criteria failed to pick up some cases of preclinical DIC compared with Japanese Ministry of Health and Welfare (JMHW) criteria, they were able to identify overt DIC [3] [18].

Dixit et al., (2007) evaluated 67 patients with acute leukaemia, they showed 33 patients (49.3\%) had prolonged prothrombin time, 57 patients (85\%) had thrombocytopenia, the platelet count at presentation was less than $50 \times 10^{9} / \mathrm{L}$ in $38 \mathrm{pa}-$ tients (56.7\%). No patients had any abnormality of fibrinogen at presentation, D-dimer was raised in 20 patients (29.9\%) at presentation [8]. Of the 48 newly diagnosed non-APL AML patients evaluated at presentation in present study, all 
Table 2. Distribution of study subjects by age \& gender.

\begin{tabular}{ccc}
\hline Age group (years) & Frequency (n) & Percent (\%) \\
\hline $16-26$ & 12 & 25.0 \\
$27-37$ & 9 & 18.8 \\
$38-48$ & 13 & 27.1 \\
$49-59$ & 6 & 12.5 \\
$60-70$ & 8 & 16.7 \\
Gender & & \\
Male & 25 & 52.1 \\
Female & 23 & 47.9 \\
\hline
\end{tabular}

Table 2 shows age \& gender distribution of study subjects. Maximum 27.1\% patients belong to the age range 38 - 48, followed by $25 \%$ in age range 16 - 26 years. Male was slightly predominant with a male: female ratio was 1.08 .

had some form abnormality of the DIC parameters (Table 3). 18 patients (37.5\%) had prolonged prothrombin time. 40 patients $(83.3 \%)$ presented with thrombocytopenia defined as a platelet count of less than $100 \times 10^{9} / \mathrm{L}$ and platelet count at presentation were less than $50 \times 10^{9} / \mathrm{L}$ in 25 patients (52.1\%). Fibrinogen levels was not found significantly low in any patients. 44 patients $(91.7 \%)$ had raised ( $>0.5)$ D-dimer and 10 patients $(20.8 \%)$ had a strong rise $(>4.0)$ of D-dimer. The finding of this study showed concordance with Dixit et al., (2007) except for D-dimer. Elevated D-dimer in $91 \%$ of patients that found in our study showed similarity with the study conducted by HU et al. (2016), Reddy et al. (1990) \& Speiser et al. (1990) who reported elevated D-dimer in over 95\%, 87.5\% and 90\% respectively [19] [20] [21]. Cielińska et al. (2000) also found elevated D-dimer in most patients, irrespective of the type of acute leukaemia [22].

Fibrinogen level was not found to be a sensitive marker for DIC screening as none of our study patients had significantly low fibrinogen $(<100 \mathrm{mg} / \mathrm{dl})$. This result was in accordance with that of ISTH observations and with other researchers (Nur S et al., 1995; Wada H et al., 2003) [3] [23]. However, a drop in the value from an earlier higher level remains a possibility. The mean PT (17.48 vs 14.87 ) \& D-dimer (5.28 vs 2.10 ) was higher in patients with DIC than without DIC and reached statistical significance $(p<0.05)$. The mean platelet count (32.14 vs 61.02$)$ \& fibrinogen (217.14 vs 324.93$)$ were lower for patients with DIC than those without DIC, but this did not reach statistical significance $(p>$ 0.05).

Study conducted by Dixit et al., (2007) found $40.3 \%$ of study patients \& $60 \%$ of patients with DIC had some bleeding manifestations at presentation [8]. The present study shows concordance with that result as 19 patients (39.6\%) of study population $\& 57 \%$ of patients with DIC had bleeding at presentation. $72 \%$ of patients with platelets less than $50 \times 10^{9} / \mathrm{L}$ had bleeding. Bleeding was found to be significantly related to thrombocytopenia ( $p$-value $<0.001$ ), rather than DIC status ( $p$-value 0.412 ). 
Table 3. Characteristic of DIC parameters of study subjects.

\begin{tabular}{ccc}
\hline Parameter & Value & Frequency (\%) \\
\hline Platelets $\left(\times 10^{9} / \mathrm{L}\right)$ & $\geq 100$ & $8(16.7 \%)$ \\
\hline PT $(\mathrm{s})$ & $<100$ & $40(83.3 \%)$ \\
\hline D-dimer $(\mu \mathrm{g} / \mathrm{ml})$ & Normal & $30(62.5 \%)$ \\
& Raised & $18(37.5 \%)$ \\
\hline Fibrinogen $(\mathrm{mg} / \mathrm{dl})$ & Normal & $4(8.3 \%)$ \\
& Raised & $44(91.7 \%)$ \\
\hline ISTH-DIC Score & $\geq 100$ & $48(100 \%)$ \\
& $<100$ & $0(0 \%)$ \\
\hline
\end{tabular}

Table 3 shows characteristics of DIC parameters of study subjects at presentation. The predominant abnormality was raised D-dimer (91.7\%), followed by thrombocytopenia (83.3\%) \& raised PT (37.5\%). None had hypofibrinogenemia. DIC (ISTH-DIC score $\geq 5$ ) was diagnosed in $14.6 \%$ of patients. PT: Prothrombin time, ISTH: International society of thrombosis and haemostasis.

The incidence of DIC in present study was $14.6 \%$ (Figure 1). These results show an incidence of DIC that is similar to that found by other authors [8] [24]. Patients were classified into DIC $(n=7)$ and Non-DIC $(n=41)$ groups. Uchiumi et al., (2007) found significant differences between the 2 groups (DIC \& non-DIC) regarding WBC counts, fibrinogen, prothrombin time ratio (INR), FDP levels and blast percentages in the bone marrow [24]. Present study found only PT and D-dimer were significantly higher in patients presented with DIC (Table 4). No significant correlation was found between DIC status and platelets count, fibrinogen levels, WBC counts, peripheral blast percentage. Also no significant association was found in respect of age, sex, bleeding at presentation.

DIC is a devastating complication of acute leukaemia, and early therapeutic intervention for DIC is warranted [25]. Therefore, efforts to identify the clinical parameters associated with DIC are important. Uchiumi H. et al. (2007) attempted to find out the relationship between DIC and the immune phenotypes of leukaemic cells [24]. A clinically important and novel finding of that study was the negative expressions of CD13 and HLA-DR were found as independent risk factors for DIC. Negative expression of HLA-DR turned out to be one such factor of present study. Flow cytometric evaluation done on 33 immunophenotyping reports available patients showed lower expression of CD117, CD34, HLA-DR in patients presented with DIC (Figure 2) and statistically significant ( $p$-value 0.034) negative expression of HLA-DR in DIC group (Table 5).

Approximately 10 to 20 percent of all cases of AML do not express HLA-DR antigens, and half of them were diagnosed to have APL [26] [27]. Leukaemic cells of APL are generally negative for HLA-DR. Of the 9 patients with negative HLA-DR that found in this study, DIC developed in 4 (44\%) patients with a relative risk of 5.34\%. Therefore, we ruled out APL for these patients by morphology 
Table 4. Comparison of clinical \& laboratory characteristics between DIC \& non-DIC groups.

\begin{tabular}{cccc}
\hline & Overt DIC & No DIC & $p$-value \\
\hline Age (years) & $37.57 \pm 23.08$ & $40.85 \pm 14.542$ & $0.617^{\mathrm{a}}$ \\
Sex (\%) & & & \\
Male & $4(57.1 \%)$ & $21(51.2 \%)$ & $1.00^{\mathrm{b}}$ \\
Female & $3(42.9 \%)$ & $20(48.8 \%)$ & \\
Bleeding at presentation & & & $0.412^{\mathrm{b}}$ \\
Present & $4(57.1 \%)$ & $15(36.6 \%)$ & \\
Absent & $3(42.9 \%)$ & $26(63.6 \%)$ & $0.200^{\mathrm{a}}$ \\
Platelets $\left(\times 10^{9} / \mathrm{L}\right)$ & $32.14 \pm 27.14$ & $61.02 \pm 57.30$ & $0.002^{\mathrm{a}}$ \\
PT(s) & $17.48 \pm 2.90$ & $14.87 \pm 1.71$ & $<0.001^{\mathrm{a}}$ \\
D-Dimer $(\mu \mathrm{g} / \mathrm{dl})$ & $5.28 \pm 2.61$ & $2.10 \pm 1.76$ & $0.071^{\mathrm{a}}$ \\
Fibrinogen $(\mathrm{mg} / \mathrm{dl})$ & $217.14 \pm 112.44$ & $324.93 \pm 146.49$ & $0.431^{\mathrm{a}}$ \\
WBC $\left(\times 10^{9} / \mathrm{L}\right)$ & $14.87 \pm 13.25$ & $25.45 \pm 34.56$ & $0.587^{\mathrm{a}}$ \\
\hline Peripheral Blast $(\%)$ & $43.57 \pm 27.79$ & $51.00 \pm 33.90$ & \\
\hline
\end{tabular}

Table 4 shows PT \& D-dimer is significantly elevated in DIC group ( $p$-value $0.002 \&<0.001$ respectively). Whereas no significant difference is found in platelets count, fibrinogen levels, age, sex, bleeding at presentation or peripheral blast percentage between DIC \& without DIC group. WBC: White blood cells, ${ }^{\text {a }}: p$-value reached from unpaired $\mathrm{t}$-test, ${ }^{\mathrm{b}}: p$-value reached from chi-squared test.

Table 5. Comparison of immunophenotypic marker expression between DIC \& non-DIC groups.

\begin{tabular}{ccccc}
\hline & & DIC & No DIC & $p$ value \\
\hline \multirow{2}{*}{ CD13 } & Positive & 4 & 22 & 0.58 \\
& Negative & 2 & 5 & 0.335 \\
\hline \multirow{2}{*}{ CD117 } & Positive & 5 & 26 & \\
& Negative & 1 & 1 & 0.61 \\
\hline \multirow{2}{*}{ MPO } & Positive & 4 & 21 & 1.00 \\
& Negative & 2 & 6 & \multirow{2}{*}{0.20} \\
CD34 & Positive & 6 & 25 & \\
& Negative & 0 & 2 & 0.034 \\
\hline \multirow{2}{*}{ HLA-DR } & Positive & 1 & 13 & 0.584 \\
& Negative & 5 & 14 & \\
\hline \multirow{2}{*}{ Aberrant } & Positive & 2 & 5 & \\
& Negative & 4 & 2 & 5 \\
\hline
\end{tabular}

Table 5 shows statistically significant ( $p$-value 0.034 ) negative expression of HLA DR in patients with DIC, $\mathrm{CD}$ : Cluster of differentiation, MPO: Myeloperoxidase, $p$-value reached from chi-squared test. 


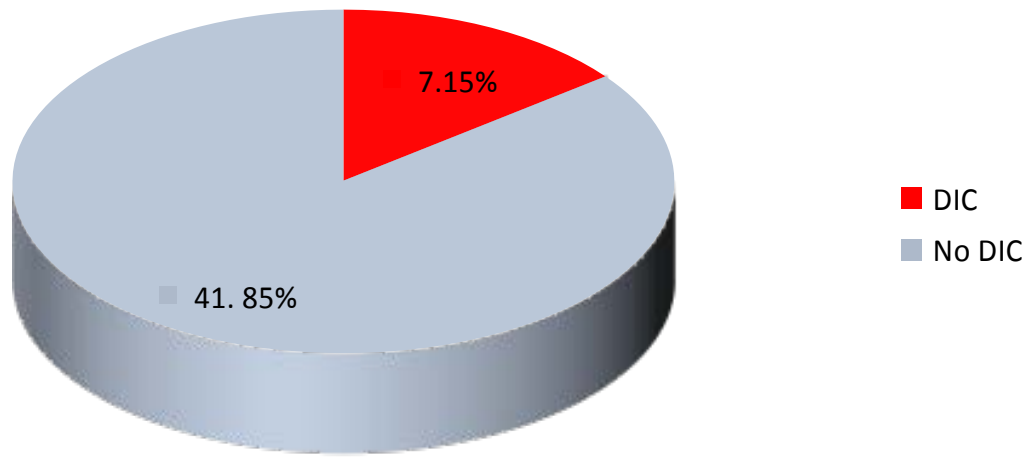

Figure 1. Pie diagram shows frequency of DIC in our study subjects.

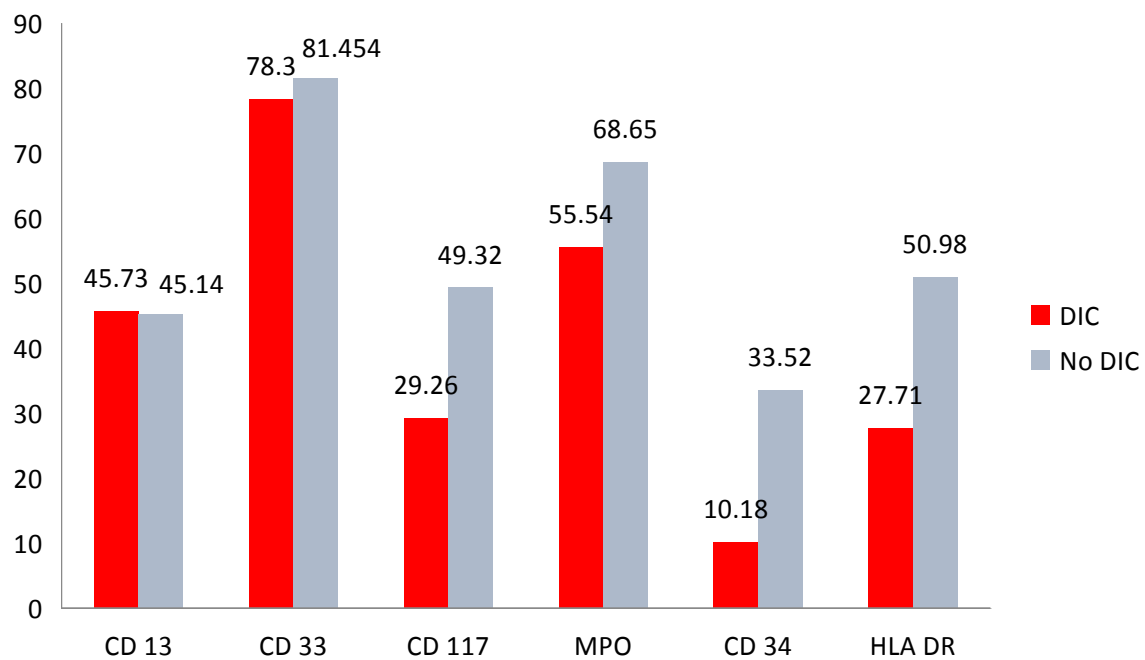

Figure 2. Bar diagram shows the comparison of mean immunophenotypic marker expression in DIC \& non-DIC group.

and cytogenetic/molecular study. Muroi et al. (1997) reported 11 HLA-DR negative non-APL AML patients to have been complicated by DIC [28]. As a result, the negative expression of HLA-DR is closely associated with the development of DIC and the effect of DIC is considered to be independent of APL.

\section{Conclusion}

In patients with AML, the presence of DIC may adversely affect the disease outcome. A significant portion of patients with DIC have no apparent symptom or bleeding. So, routine screening of DIC parameter at presentation is recommended for early diagnosis \& effective management of DIC in AML patients. Extensive evaluation of clinical \& laboratory parameters is recommended too for identifying factors associated with the development of DIC.

\section{Acknowledgements}

The authors acknowledge the Department of Haematology, Bangabandhu Sheikh Mujib Medical University, Dhaka, Bangladesh for kind cooperation. 


\section{Conflicts of Interest}

The authors declare no conflicts of interest regarding the publication of this paper.

\section{References}

[1] Döhner, H., Weisdorf, D.J. and Bloomfield, C.D. (2015) Acute Myeloid Leukemia. The New England Journal of Medicine, 373, 1136-1152. https://doi.org/10.1056/NEJMra1406184

[2] Taylor, F.B., Toh, C.H., Hoots, K.W., Wada, H. and Levi, M. (2001) Towards Definition, Clinical and Laboratory Criteria, and a Scoring System for Disseminated Intravascular Coagulation. Thrombosis and Haemostasis, 86, 1327-1330. https://doi.org/10.1055/s-0037-1616068

[3] Wada, H., Gabazza, E.C., Asakura, H., Koike, K., Okamoto, K., Maruyama, I., Shiku, H. and Nobori, T. (2003) Comparison of Diagnostic Criteria for Disseminated Intravascular Coagulation (DIC): Diagnostic Criteria of the International Society of Thrombosis and Hemostasis (ISTH) and of the Japanese Ministry of Health and Welfare for Overt DIC. American Journal of Hematology, 74, 17-22. https://doi.org/10.1002/ajh.10377

[4] Falanga, A. and Rickles, F.R. (1999) Pathophysiology of the Thrombophilic State in the Cancer Patient. Seminars in Thrombosis and Hemostasis, 25, 173-182 https://doi.org/10.1055/s-2007-994919

[5] Barbui, T. and Falanga, A. (2001) Disseminated Intravascular Coagulation in Acute Leukemia. Seminars in Thrombosis and Hemostasis, 27, 593-604. https://doi.org/10.1055/s-2001-18865

[6] Rickles, F.R., Levine, M. and Edwards, R.L. (1992) Hemostatic Alterations in Cancer Patients. Cancer and Metastasis Reviews, 11, 237-248. https://doi.org/10.1007/BF01307180

[7] Falanga, A., Barbui, T., Rickles, F.R. and Levine, M.N. (1993) Guidelines for Clotting Studies in Cancer Patients. Thrombosis and Haemostasis, 70, 540-542.

https://doi.org/10.1055/s-0038-1649619

[8] Dixit, A., Chatterjee, T., Mishra, P., Kannan, M., Choudhry, D.R., Mahapatra, M., Choudhry, V.P. and Saxena, R. (2007) Disseminated Intravascular Coagulation in Acute Leukemia at Presentation and during Induction Therapy. Clinical and Applied Thrombosis/ Hemostasis, 13, 292-298. https://doi.org/10.1177/1076029607302435

[9] Gando, S., Wada, H., Asakura, H., Iba, T., Eguchi, Y., Okamoto, K., Ohtomo, Y., Kawasugi, K., Koga, S., Koseki, K. and Tsuji, H. (2005) Evaluation of New Japanese Diagnostic Criteria for Disseminated Intravascular Coagulation in Critically Ill Patients. Clinical and Applied Thrombosis/ Hemostasis, 11, 71-76. https://doi.org/10.1177/107602960501100108

[10] Matsumoto, T., Wada, H., Nishioka, Y., Nishio, M., Abe, Y., Nishioka, J., Kamikura, Y., Sase, T., Kaneko, T., Houdijk, W.P. and Nobori, T. (2006) Frequency of Abnormal Biphasic aPTT Clot Waveforms in Patients with Underlying Disorders Associated with Disseminated Intravascular Coagulation. Clinical and Applied Thrombosis/Hemostasis, 12, 185-192. https://doi.org/10.1177/107602960601200206

[11] Bakhtiari, K., Meijers, J.C., de Jonge, E. and Levi, M. (2004) Prospective Validation of the International Society of Thrombosis and Haemostasis Scoring System for Disseminated Intravascular Coagulation. Critical Care Medicine, 32, 2416-2421. 
https://doi.org/10.1097/01.CCM.0000147769.07699.E3

[12] Sivula, M., Tallgren, M. and Pettilä, V. (2005) Modified Score for Disseminated Intravascular Coagulation in the Critically Ill. Intensive Care Medicine, 31, 1209-1214. https://doi.org/10.1007/s00134-005-2685-2

[13] Cauchie, P., Cauchie, C., Boudjeltia, K.Z., Carlier, E., Deschepper, N., Govaerts, D., Migaud-Fressart, M., Woodhams, B. and Brohée, D. (2006) Diagnosis and Prognosis of Overt Disseminated Intravascular Coagulation in a General Hospital-Meaning of the ISTH Score System, Fibrin Monomers, and Lipoprotein-C-Reactive Protein Complex Formation. American Journal of Hematology, 81, 414-419. https://doi.org/10.1002/ajh.20597

[14] Libourel, E.J., Klerk, C.P., van Norden, Y., de Maat, M.P., Kruip, M.J., Sonneveld, P., Löwenberg, B. and Leebeek, F.W. (2016) Disseminated Intravascular Coagulation at Diagnosis Is a Strong Predictor for Thrombosis in Acute Myeloid Leukemia. Blood, 128, 1854-1861. https://doi.org/10.1182/blood-2016-02-701094

[15] Toh, C.H., Hoots, W.K. and SSC on Disseminated Intravascular Coagulation of the ISTH (2007) The Scoring System of the Scientific and Standardisation Committee on Disseminated Intravascular Coagulation of the International Society on Thrombosis and Haemostasis: A 5-Year Overview. Journal of Thrombosis and Haemostasis, 5, 604-606. https://doi.org/10.1111/j.1538-7836.2007.02313.x

[16] Gralnick, H.R., Marchesi, S. and Givelber, H. (1972) Intravascular Coagulation in Acute Leukemia: Clinical and Subclinical Abnormalities. Blood, 40, 709-718. https://doi.org/10.1182/blood.V40.5.709.709

[17] Bick, R.L. (1988) Disseminated Intravascular Coagulation and Related Syndromes: A Clinical Review. Seminars in Thrombosis and Hemostasis, 14, 299-338. https://doi.org/10.1055/s-2007-1002793

[18] Kobayashi, N., Maekawa, T., Takada, M., Tanaka, H. and Gonmori, H. (1983) Criteria for Diagnosis of DIC Based on the Analysis of Clinical and Laboratory Findings in 345 DIC Patients Collected by the Research Committee on DIC in Japan. Bibliotheca Haematologica, 49, 265-275. https://doi.org/10.1159/000408467

[19] Hu, W., Wang, X. and Yang, R. (2016) Evaluation of D-Dimer and Lactate Dehydrogenase Plasma Levels in Patients with Relapsed Acute Leukemia. Oncology Letters, 12, 591-596. https://doi.org/10.3892/ol.2016.4657

[20] Reddy, V.B., Kowal-Vern, A., Hoppensteadt, D.A., Kumar, A., Walenga, J.M., Fareed, J. and Harold, R.S. (1990) Global and Molecular Hemostatic Markers in Acute Myeloid Leukemia. American Journal of Clinical Pathology, 94, 397-403. https://doi.org/10.1093/ajcp/94.4.397

[21] Speiser, W., Pabinger-Fasching, I., Kyrle, P.A., Kapiotis, S., Kottas-Heldenberg, A., Bettelheim, P. and Lechner, K. (1990) Hemostatic and Fibrinolytic Parameters in Patients with Acute Myeloid Leukemia: Activation of Blood Coagulation, Fibrinolysis and Unspecific Proteolysis. Blut, 61, 298-302.

https://doi.org/10.1007/BF01732881

[22] Cielińska, S., Urbaniak-Kujda, D., Kiełbiński, M., Milczarska, J. and Kuliczkowski, K. (2000) Observation of D-Dimer Levels in Serum of Patients with Acute Leukemia. Polskie Archiwum Medycyny Wewnetrznej, 103, 7-14.

[23] Nur, S., Anwar, M., Saleem, M. and Ahmad, P.A. (1995) Disseminated Intravascular Coagulation in Acute Leukaemias at First Diagnosis. European Journal of Haematology, 55, 78-82. https://doi.org/10.1111/j.1600-0609.1995.tb01813.x

[24] Uchiumi, H., Matsushima, T., Yamane, A., Doki, N., Irisawa, H., Saitoh, T., Sakura, T., Jimbo, T., Handa, H., Tsukamoto. N. and Karasawa, M. (2007) Prevalence and 
clinical Characteristics of Acute Myeloid Leukemia Associated with Disseminated Intravascular Coagulation. International Journal of Hematology, 86, 137-142. https://doi.org/10.1532/IJH97.06173

[25] Törnebohm, E., Blombäck, M., Lockner, D., Egberg, N. and Paul, C. (1992) Bleeding Complications and Coagulopathy in Acute Leukaemia. Leukemia Research, 16, 1041-1048. https://doi.org/10.1016/0145-2126(92)90084-K

[26] Kaleem, Z., Crawford, E., Pathan, M.H., Jasper, L., Covinsky, M.A., Johnson, L.R. and White, G. (2003) Flow Cytometric Analysis of Acute Leukemias: Diagnostic Utility and Critical Analysis of Data. Archives of Pathology \& Laboratory Medicine, 127, 42-48. https://doi.org/10.5858/2003-127-42-FCAOA

[27] Wetzler, M., McElwain, B.K., Stewart, C.C., Blumenson, L., Mortazavi, A., Ford, L.A., Slack, J.L., Barcos, M., Ferrone, S. and Baer, M.R. (2003) HLA-DR Antigen-Negative Acute Myeloid Leukemia. Leukemia, 17, 707-715.

https://doi.org/10.1038/sj.leu.2402865

[28] Muroi, K.A., Yoshida, M.I., Suzuki, T.O., Amemiya, Y.O., Hatake, K.I. and Miura, Y.A. (1997) Clinicopathological Features in HLA-DR-Negative Acute Myeloid Leukemia. The Japanese Journal of Clinical Hematology, 38, 631-637. 